\title{
Barriers and Facilitators to the Implementation of eHealth Services: Systematic Literature Analysis
}

Björn Schreiweis ${ }^{1,2}$, Dr sc hum; Monika Pobiruchin ${ }^{2,3}$, Dr sc hum; Veronika Strotbaum ${ }^{2,4}$, MA; Julian Suleder ${ }^{2,5}$, MSc; Martin Wiesner, ${ }^{2,6}$, Dipl-Inform Med; Björn Bergh ${ }^{1}$, Dr med

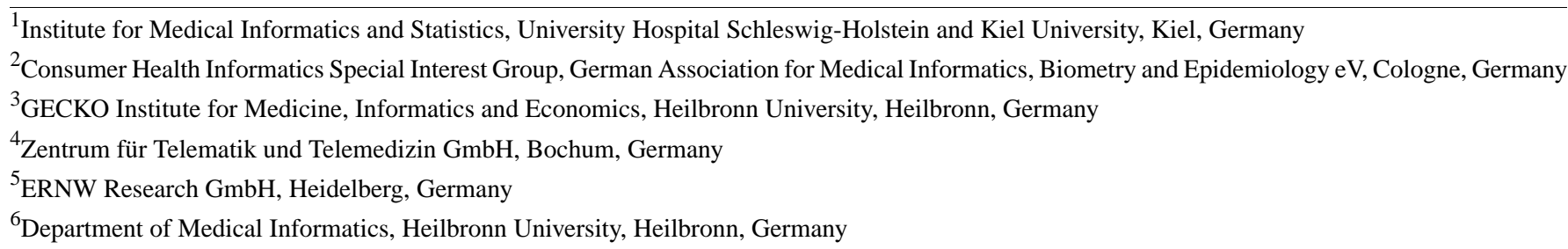

\section{Corresponding Author:}

Björn Schreiweis, Dr sc hum

Institute for Medical Informatics and Statistics

University Hospital Schleswig-Holstein and Kiel University

Arnold-Heller-Straße 3

Kiel, 24105

Germany

Phone: 49431500 ext 30701

Fax: 4943150030704

Email: bjoern.schreiweis@uksh.de

\section{Abstract}

Background: The field of eHealth has a history of more than 20 years. During that time, many different eHealth services were developed. However, factors influencing the adoption of such services were seldom the main focus of analyses. For this reason, organizations adopting and implementing eHealth services seem not to be fully aware of the barriers and facilitators influencing the integration of eHealth services into routine care.

Objective: The objective of this work is to provide (1) a comprehensive list of relevant barriers to be considered and (2) a list of facilitators or success factors to help in planning and implementing successful eHealth services.

Methods: For this study, a twofold approach was applied. First, we gathered experts' current opinions on facilitators and barriers in implementing eHealth services via expert discussions at two health informatics conferences held in Europe. Second, we conducted a systematic literature analysis concerning the barriers and facilitators for the implementation of eHealth services. Finally, we merged the results of the expert discussions with those of the systematic literature analysis.

Results: Both expert discussions (23 and 10 experts, respectively) identified 15 barriers and 31 facilitators, whereas 76 barriers and 268 facilitators were found in 38 of the initial 56 articles published from 12 different countries. For the analyzed publications, the count of distinct barriers reported ranged from 0 to 40 (mean 10.24, SD 8.87, median 8). Likewise, between 0 and 48 facilitators were mentioned in the literature (mean 9.18, SD 9.33, median 6). The combination of both sources resulted in 77 barriers and 292 facilitators for the adoption and implementation of eHealth services.

Conclusions: This work contributes a comprehensive list of barriers and facilitators for the implementation and adoption of eHealth services. Addressing barriers early, and leveraging facilitators during the implementation, can help create eHealth services that better meet the needs of users and provide higher benefits for patients and caregivers.

(J Med Internet Res 2019;21(11):e14197) doi: $\underline{10.2196 / 14197}$

\section{KEYWORDS}

eHealth; health information interoperability; policy; software design 


\section{Introduction}

\section{Background}

In 1999, the term eHealth was coined. The first publications defined it as a "new term needed to describe the combined use of electronic communication and information technology in the health sector. The use in the health sector of digital data-transmitted, stored, and retrieved electronically-for clinical, educational, and administrative purposes, both at the local site and at a distance" [1].

With the evolution of an increasing number of e-services, health care is providing many different eHealth services. In general, eHealth is associated with a positive influence on health care outcomes [2]. Improved cost-effectiveness, more information on a patient's health status, and better communication between health care professionals are just some examples of the benefits of eHealth services $[3,4]$. However, there is no consistent picture of eHealth services' adoption and broad acceptance. Often, eHealth services are not adopted and lack acceptance by their users [5]. However, for several services, domains, or patient groups, the levels of acceptance and related adoption rates are reported to be higher [6].

For several years, health care institutions have evaluated and started to use eHealth services to support patient care. The evolution of mobile phones and the broad availability of apps for prevention, wellness, and fitness scenarios has resulted in an increased importance of eHealth for the health care industry because these new services help to better support care processes $[7,8]$. Both the primary and secondary health care markets are important when it comes to eHealth services. With eHealth being an important economic factor, member countries of the Organisation for Economic Co-operation and Development spend an average of $8.9 \%$ of their gross domestic product on health [9]. In addition, start-ups and "big players" (eg, Google, Apple, Facebook, Amazon, and Microsoft) [10] play an important role in the eHealth economy. These economic factors drive changes in eHealth legislation in national health care systems, such as the eHealth Act in Germany and the Electronic Patient Record Act in Switzerland [11].

Several models are available to evaluate the use of technology (eg, Technology Acceptance Model [12] and Unified Theory of Acceptance and Use of Technology [13]), which are often adapted for evaluation in the eHealth domain [14,15]. Such models provide criteria for the evaluation of technology acceptance. The use of eHealth in routine care can be explained to a certain extent by these models [14-16]. However, those models may benefit from several additions and modifications, especially in relation to implementation.

Several reviews and projects have identified barriers and facilitators for eHealth service adoption in certain environments and disease contexts, such as mental health [17-19], veterans health care [20-22], and hypertension [23-25]. However, to the best of our knowledge, no overview, meta-analysis, or comprehensive list of barriers and facilitators affecting the adoption of eHealth services has been conducted and published.
For this reason, we organized two expert workshops and related discussion rounds to obtain an overview of the barriers and facilitators for the adoption of eHealth services. Both workshops were independent of a specific scenario and were accompanied by an exhaustive literature analysis.

\section{Objective}

The objective of this work is twofold: to provide (1) a comprehensive list of barriers to be considered, and (2) a list of facilitators or success factors to help in planning and implementing eHealth services. It is not within the scope of this paper to provide another model for evaluating eHealth or telemedicine services.

\section{Methods}

\section{Overview}

Two different approaches were combined in this study. First, we wanted to obtain international experts' current opinions on facilitators and barriers toward the implementation of eHealth services. This step helped to identify immediate experiences and knowledge bases especially from experts from countries with a higher level of digitization in health care. Second, we were interested in facilitators and barriers for implementation in completed projects and initiatives. Thus, two rounds of expert discussions at health informatics conferences in Europe were organized and held. Finally, a systematic literature analysis on barriers and facilitators for the implementation and adoption of eHealth applications was conducted.

\section{Expert Discussions}

Two expert discussions were organized at conferences in Europe: (1) Medical Informatics Europe (MIE) 2015 in Madrid, Spain, and (2) eHealth Innovation Days (eHID) 2017 in Flensburg, Germany.

The MIE 2015 expert discussion in Madrid included 23 international experts from the field of medical and health informatics (15 participants from Europe; 5 from the Middle East, Asia, and America; and 3 German organizers). The primary topic of the expert discussion was "Consumer Health Informatics: Barriers and Facilitators of eHealth Usage Among Consumers." The discussion included three short introduction talks, followed by three discussion groups on barriers for eHealth use among consumers [26]. However, due to time constraints resulting from the workshop format, the discussion mostly focused on barriers. Each group separately discussed the barriers to the use of eHealth applications and wrote them down on prompt cards. Once the discussions of five small groups were finished, each group presented their results briefly. The organizers of the expert discussion collected and aggregated the results in the format of a short workshop report [26].

The second expert discussion, on the topic of "Success Factors for Consumer-Centered eHealth Services," was held in Flensburg, Germany. Participants were experts in the fields of medical and health informatics located in the Baltic Sea region, especially Sweden, Finland, Estonia, and Germany. An introduction followed by two short keynote talks constituted a starting point for the experts changing their perspective to one 
of five stakeholder groups. There were stakeholder groups for (1) citizens, patients, and family members (3 experts); (2) start-ups and application developers (4 experts); (3) researchers (3 experts); (4) policy makers and politicians ( 0 experts); and (5) data privacy officers and chief information officers (CIOs) (0 experts). The stakeholder groups for policy makers and politicians, as well as data privacy officers and CIOs were planned but were called off ( 0 participants). Each stakeholder group brainstormed on the success factors and facilitators for consumer-centric eHealth application use and/or its implementation. Next, each group presented briefly, and all groups discussed the results in a panel format. The results of each group were collected via flipcharts and consolidated by the authors in similar formats as the results of the first expert workshop held during MIE 2015.

\section{Literature Analysis}

To identify relevant articles in the field, a PubMed search was conducted on May 28, 2018, including the following query terms: (("telemedicine"[MeSH Terms] OR "telemedicine"[All
Fields] OR “ehealth"[All Fields]) AND (“adoption”[MeSH Terms] OR “adoption”[All Fields]) AND barriers[All Fields] AND facilitators[All Fields]) AND (("patients"[MeSH Terms] OR "patients"[All Fields]) OR consumers[All Fields]).

The time frame for potentially relevant articles was only limited by the search date. All articles published before this retrieval date were considered relevant. The resulting literature was filtered by scanning for actual mentions of barriers or facilitators for the adoption or implementation of any kind of eHealth application (see Textbox 1). In this context, titles, abstracts, and full-text articles were read to determine whether the article met the aforementioned criteria. For all identified papers, barriers and facilitators were extracted manually by one of the authors. Barriers and facilitators were listed in an Excel spreadsheet (see Multimedia Appendix 1). Next, a categorization was applied creating a mind map for barriers and facilitators separately (see Multimedia Appendix 2). This categorization was based on the three main categories as identified by Griebel et al [26]: (1) individual, (2) environmental and organizational, and (3) technical.

Textbox 1. Criteria for the inclusion and exclusion criteria of literature in the analysis.

Inclusion criteria

- $\quad$ Published and listed on PubMed as of May 28, 2018

- Listing barriers for the implementation or adoption of eHealth services and/or listing success factors/facilitators for the implementation or adoption of eHealth services

- Articles in English and German

Exclusion criteria

- Article about research protocols of a planned study (ie, no results on barriers and/or facilitators)

- Abstract not available

- $\quad$ Article not about eHealth services

- $\quad$ Full text not accessible

\section{Comparison of Expert Discussions and Literature Analysis}

One expert in the field of medical informatics categorized the barriers identified in the literature according to the categories provided by the study of Griebel et al [26] and extended the original mind map with the results from the literature analysis conducted for this study. The success factors for eHealth service adoption identified in the literature were categorized using the main categories (individual, environmental and organizational, and technical) in accordance with the categorization of barriers. The subcategorization of the results of the expert discussions refining the three categories was done where applicable and subsequently reviewed by a coauthor. The mind map, originally generated with results from the expert discussion on success factors, was then augmented with items found in the literature. Finally, the aggregated results of the Griebel et al study [26] were extended with the results from the expert workshop on success factors, with facilitators found in the literature, and displayed in a hierarchical form (mind map).

\section{Results}

Results of the findings of the expert discussions are outlined first, followed by the results from the literature review. Both result sets are then compared for common and different attributes.

\section{Expert Discussions}

The expert discussion concerning barriers for eHealth services resulted in three categories of barriers: (1) individual, (2) environmental and organizational, and (3) technical barriers (see Figure 1). The category of individual barriers aggregated cognitive, motivational, accessibility, and trust-related barriers of individual consumers. Financial issues, political barriers, and organizational structures formed the category of environmental and organizational barriers. Unsuited services or design not fitting to the users' needs were among the technical barriers. Security concerns were another barrier because often systems and network-enabled medical devices fail to provide an acceptable level of security. Additionally, system language, missing support (who to call for help?), missing standards (both for patient data and for data exchange), and missing system 
feedback leading to unclear benefits were mentioned as barriers for eHealth services.

The expert discussion focusing on success factors and facilitators of consumer-centric eHealth services resulted in similar categories (individual success factors, environmental success factors, and technical success factors) (see Figure 2). We identified 31 success factors in the expert discussions. Subcategories of the individual success factors were a clear benefit of the service, trusting and controlling the service, the collaboration via the service, the service's user experience, and that the service facilitates research. Flexible funding, health outcomes, policies for using generated data for research, competition, and supporting laws and regulations were the subcategories of environmental success factors. Usability, standards, security, and reliability of the service were subcategories of technical success factors.

Figure 1. Barriers of eHealth usage among consumers identified in the first expert discussion at MIE 2015.

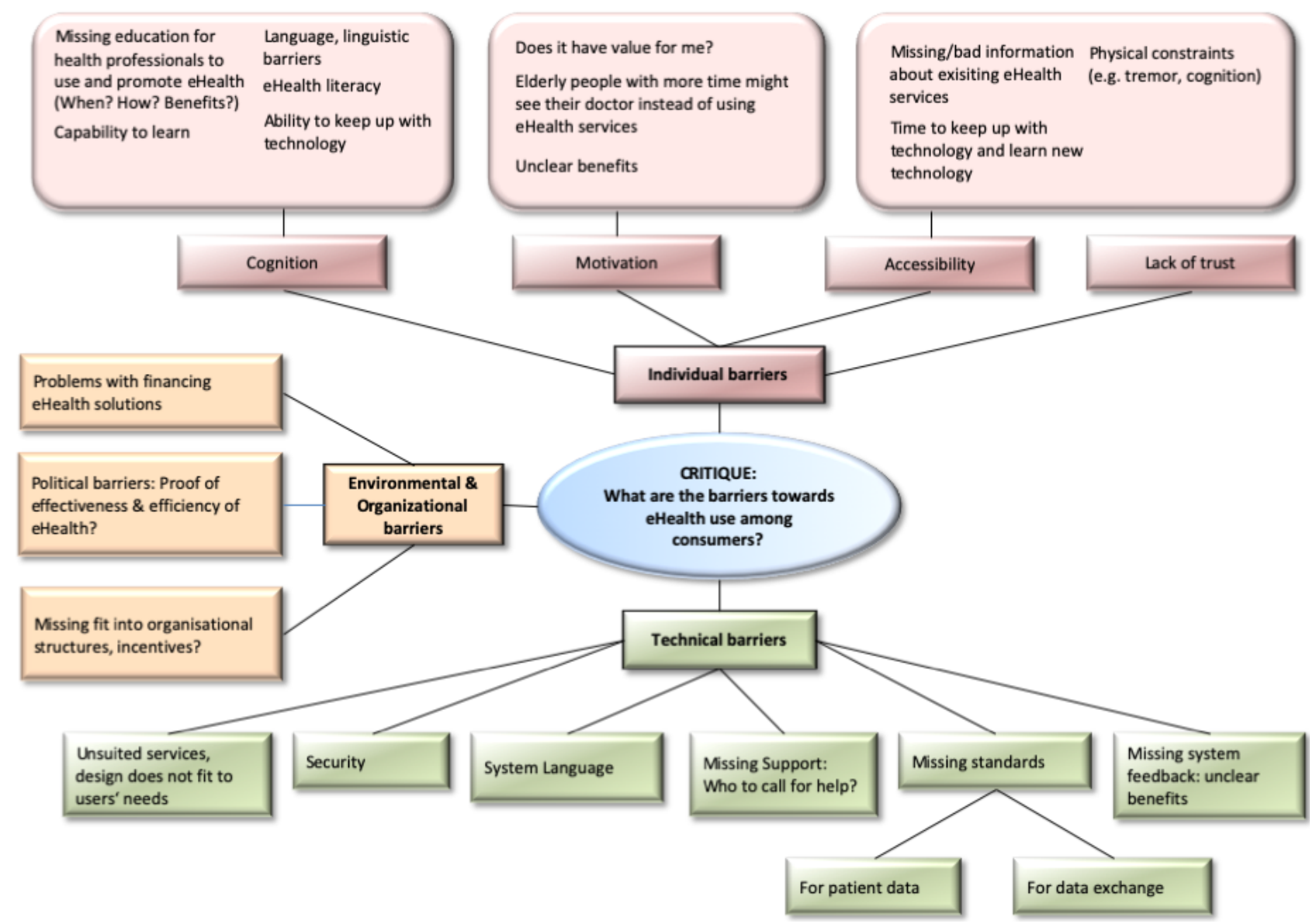


Figure 2. Success factors for consumer-centric eHealth services identified in the second expert discussion at eHID.

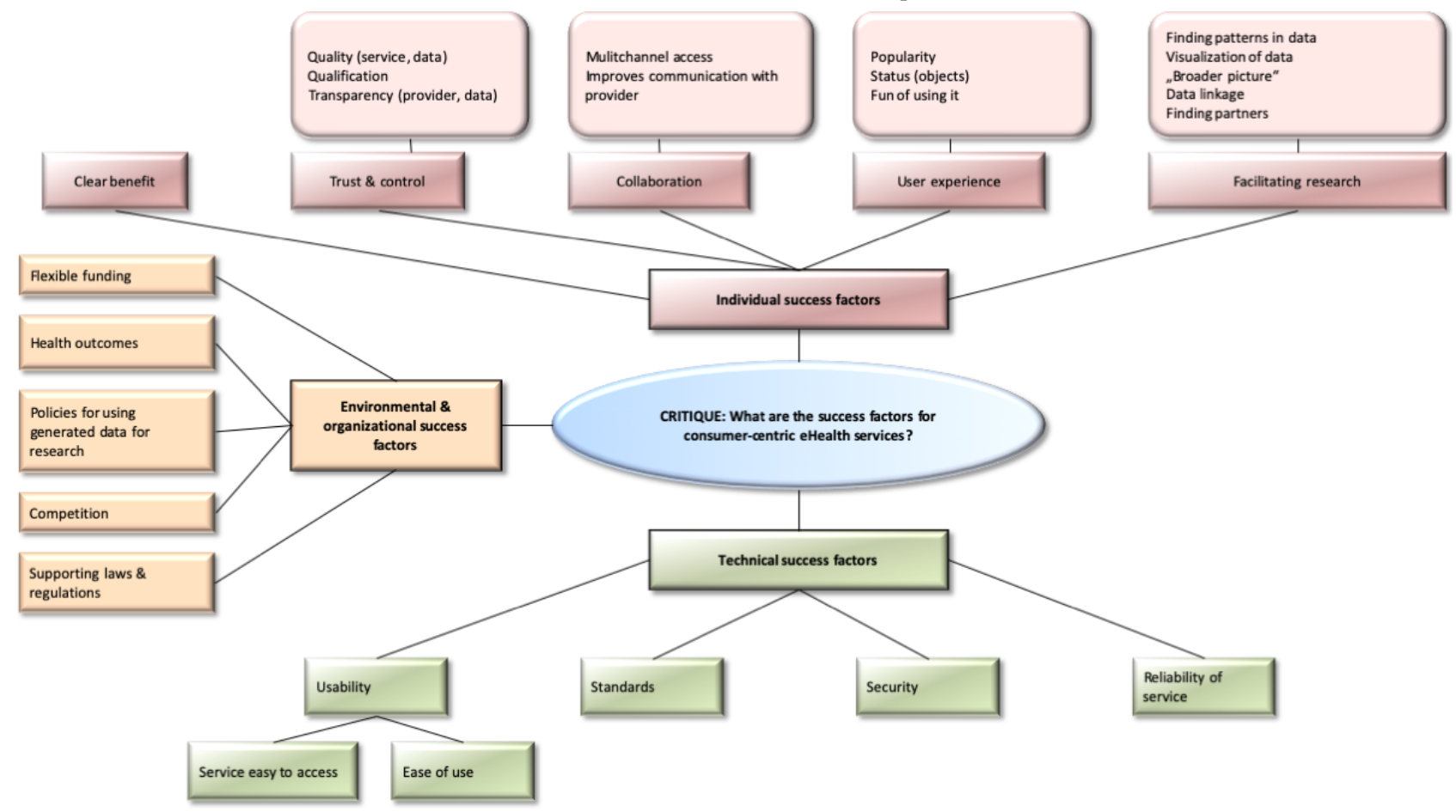

\section{Literature Analysis}

The literature analysis resulted in 56 publications published between December 27, 2007, and May 3, 2018. Of these publications, 38 were found to be relevant with full texts accessible to the authors for in-depth analyses [17-25,27-55] (see Figure 3). For the excluded 18 publications, either the full text was not accessible to the authors $(n=8)$ or the articles did not describe, analyze, or present results about barriers or facilitators for the use of eHealth applications $(n=10)$ (exclusion criteria see Textbox 1).

Figure 3. Flowchart for the identification of articles meeting the inclusion or exclusion criteria (see Textbox 1).

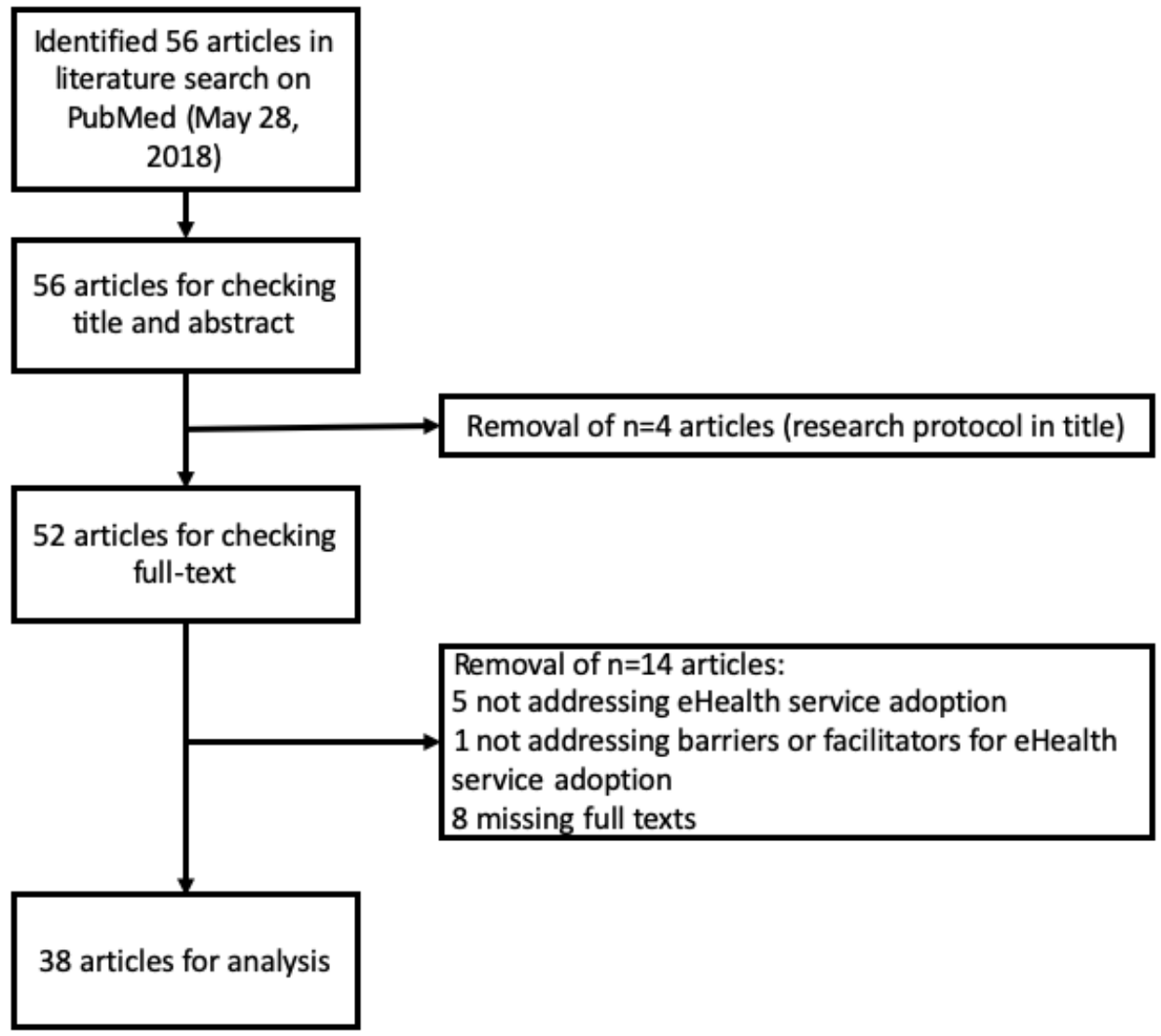


Publications, including the ones missing full text $(n=8)$, originated mostly from the United States $(19 / 46,41 \%$, published 2011-2018), followed by the Netherlands $(6 / 46,13 \%$, published 2014-2018), Canada (5/46, 10\%, published 2015-2017), the United Kingdom (5/46, 10\%, published 2016-2017), Australia (3/46, 6\%, published 2014-2015), and Norway (2/46, 4.35\%, published 2015). Ghana (published 2017), Belgium (published 2016), Ireland (published 2015), Swaziland (published 2015), Europe (published 2013), and Finland (published 2008) each had one publication in this literature analysis $(1 / 46,2 \%$; see Figure 4).

Figure 4. Included publications (before removal of missing full texts) by year and geographical location.

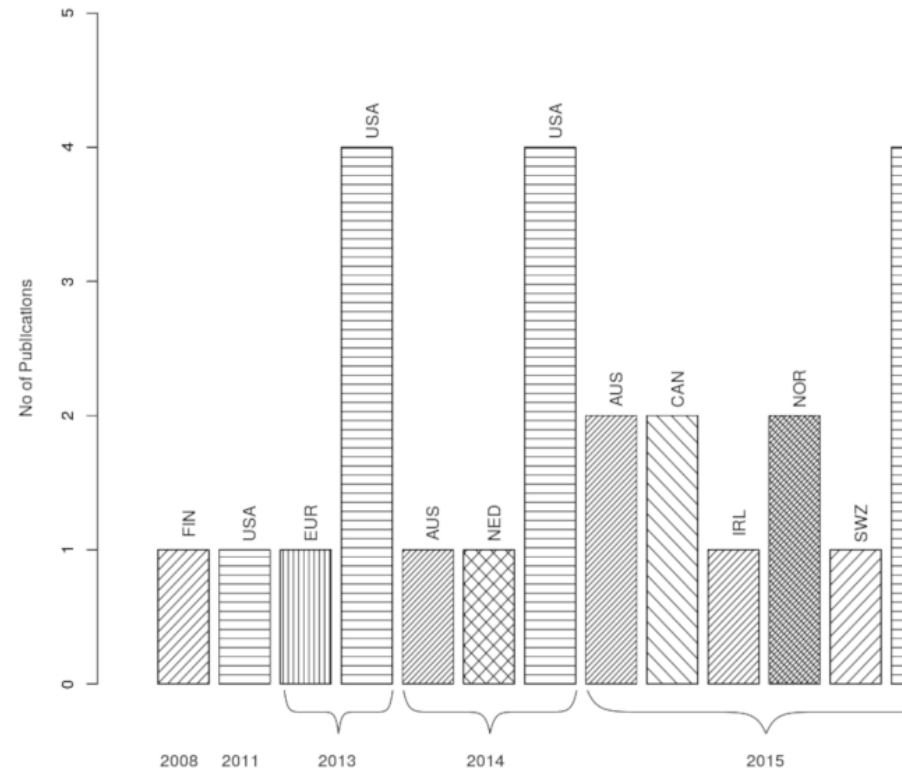

We identified 76 distinct barriers (33 individual, 25 environmental, and 18 technical) and a total of 268 facilitators (131 individual, 101 environmental, and 36 technical) in the literature (see Multimedia Appendix 1). The most frequent barrier in the literature was limited exposure/knowledge of eHealth (ie, poor digital health literacy) with 16 references [17,19-22,32,33,36,38,40,41,43,47,48,51,55], followed by 15 references of lack of necessary devices [19,20,22,24,32,37,

$38,40,41,43,44,48,51,53,55]$, and problems with financing eHealth solutions [17-19,21,24,27,28, 33,38,39,42,47]. For a complete list of the top 10 barriers, see Table 1 .

Ease of use was the most stated success factor found in the literature with seven references [20,30,33,43,44,47,53], followed by improves communication $[23,28,35,44,55]$. For a list of the top six facilitators, see Table 2.

Table 1. List of top 10 barriers mentioned in the literature.

\begin{tabular}{|c|c|c|c|}
\hline Position & Perceived barrier & Mentions, $\mathrm{n}$ & References \\
\hline 1 & $\begin{array}{l}\text { Limited exposure/knowledge of eHealth } \\
\text { (eg, poor digital health literacy) }\end{array}$ & 16 & {$[17,19-22,32,33,36,38,40,41,43,47,48,51,55]$} \\
\hline 2 & Lack of necessary devices & 15 & {$[19,20,22,24,32,37,38,40,41,43,44,48,51,53,55]$} \\
\hline 2 & Problems with financing eHealth solutions & 15 & {$[17-19,21,24,27,28,33,38,39,42,47]$} \\
\hline 4 & Cognition & 13 & {$[19,23,24,30,36-38,44,47,51-54]$} \\
\hline 4 & Security & 13 & {$[17,24,28,32-35,38-40,43,51,55]$} \\
\hline 6 & Motivation & 12 & {$[17,23,24,36,39-41,43-45,53,55]$} \\
\hline 7 & Accessibility & 10 & {$[23,36,38,39,43,46,47,51,53,55]$} \\
\hline 8 & $\begin{array}{l}\text { Unsuited services, design does not fit } \\
\text { users' needs }\end{array}$ & 9 & {$[24,33,35,38,43,46,47,52,53]$} \\
\hline 8 & Confidentiality & 9 & {$[17,23,30-34,40,51]$} \\
\hline 10 & $\begin{array}{l}\text { Missing fit into organizational structures, } \\
\text { incentives }\end{array}$ & 8 & {$[18,24,25,27,28,42,45,47]$} \\
\hline 10 & Added workload & 8 & {$[23,24,28,29,38,39,44,54]$} \\
\hline
\end{tabular}


Table 2. List of the top six facilitators mentioned in literature ${ }^{\mathrm{a}}$.

\begin{tabular}{llll}
\hline Position & Perceived facilitator & Mentions, $\mathrm{R}$ & References \\
\hline 1 & Ease of use & 7 & {$[20,30,33,43,44,47,53]$} \\
2 & Improves communication & 5 & {$[23,28,35,44,55]$} \\
2 & Motivation & 5 & {$[23,36,47,52,53]$} \\
2 & Integrated into care & 5 & {$[24,25,28,33,35]$} \\
5 & Involvement of all relevant stakeholders & 4 & {$[18,25,47,54]$} \\
6 & Availability of resources & 3 & {$[19,25,54]$} \\
6 & User-friendliness & 3 & {$[27,36,39]$} \\
\hline
\end{tabular}

${ }^{\mathrm{a}}$ There were too many facilitators mentioned twice in the literature to list them all because it would make the table too long and difficult to read.

Only one of the included articles did not list any barriers [49], whereas three articles did not identify any facilitators [17,40,48]. For the analyzed publications, the count of distinct barriers reported ranged from 0 to 40 [24] (mean 10.24, SD 8.87, median 8). Likewise, between 0 and 48 facilitators [24] were mentioned in the literature (mean 9.18, SD 9.33, median 6).

\section{Comparison of Expert Discussions and Literature Analysis}

The combination of the expert discussions ( 15 barriers) and literature analysis $(n=76)$ yielded a total of 77 specific barriers. In sum, 292 facilitators or success factors were found during the expert discussions $(n=31)$ and via the literature analysis $(n=268)$.

All barriers identified in the literature could be matched to the main categories (individual barriers, environmental barriers, technical barriers) defined in the Griebel et al study [26]. The technical barriers category was also mentioned in Mileski et al [24]. In mapping barriers from the expert discussions and literature analysis, we found that all but one barrier resulting from the expert discussions-system language (ie, the language of the service in use, such as German or English)—were also covered by the literature.

Facilitators derived from the literature could also be mapped completely to the adapted main categories from Griebel et al [26].

\section{Discussion}

\section{Principal Results}

Several references in the literature report specific barriers of eHealth adoption and implementation (eg, missing eHealth strategies $[19,33,38])$. However, distinct success factors are only included in one or two references (eg, clear governance of national eHealth strategy [32]).

Although 24 success factors from the expert discussions were not included in the results of our literature analysis, only one barrier identified in the expert discussions (system language) was not found via the literature analysis in this study. Thus, the overlap of success factors between the literature analysis and expert discussions was smaller than for barriers.

The top 10 barriers (see Table 1) and top six facilitators (see Table 2) as identified by their mention in the literature analysis can be named important factors influencing the implementation and adoption of eHealth services. The remaining factors seem to be more specific to certain stakeholders or areas of application since eHealth is a large field.

We identified many more success factors than barriers for the adoption of eHealth services. One reason behind this finding might be that success factors are outlined to a greater extent and in higher detail compared with barriers, which are reported very coarse-grained. Publication bias could be another reason. Unsuccessful projects tended not to analyze the reasons for failure, or at least not to publish their insights, compared with successful projects. For example, the Good eHealth Report [56] lists lessons learned, but the case studies published are only successful ones. For example, the reasons for the delay of the German Telematics Infrastructure and services are not published in scientific studies at all.

\section{Limitations}

The expert workshops were held only in Europe, which might have led to an underrepresentation of American, African, and Asian input to the discussions. Apart from PubMed, no further literature databases were consulted for this study. In addition, only one search with several parameters was conducted. However, the search parameters were adjusted several times to allow for more relevant articles to be found. Therefore, articles were randomly checked in the process. The literature analysis was restricted by search parameters including "barriers", and "facilitators" as well as "adoption" and "implementation," which resulted in fewer articles found in the initial search. This also led to exclusion of fewer articles from the resulting list of publications because of irrelevance according to the chosen inclusion and exclusion criteria. Moreover, no white papers or reports by governments or other organizations were considered. Blog posts and articles by security professionals or operators and developers of these services, for example, were not included. A more comprehensive investigation with a focus on the aforementioned roles could consider these sources as well.

The categorization of barriers and facilitators was done by only one of the authors based on Griebel et al [26]. Thus, interrater reliability cannot be presented.

\section{Comparison With Prior Work}

The literature analysis included several systematic reviews conducted by other researchers. However, these reviews were 
either focused on a specific eHealth application, disease, or patient subgroup. Kruse et al [20], for example, reviewed articles limited to military veterans with posttraumatic stress disorder to find out about factors that would influence telemedicine adoption. Mileski et al [24] focused their review on telemedicine for the self-management of hypertension. The systematic review by Ross et al [57] was limited to systematic reviews on factors influencing the implementation of eHealth published between 2009 and 2014. Ross et al searched with "MEDLINE, EMBASE, CINAHL, PsychINFO, and the Cochrane Library"-different databases than this study—so the relevant systematic reviews included in their study are only to a limited extent part of our literature analysis because we only searched PubMed. Ross et al used different categories for factors influencing the implementation of eHealth services informed by the Consolidated Framework for Implementation Research: innovation characteristics, outer setting, inner setting, characteristics of individuals, and process. Within these categories, Ross et al included components from all our top-level categories (individual, environmental and organizational, technical), such as adaptability and complexity (technical), and cost (environmental and organizational). Outer and inner setting, as described by Ross et al, would be included in environmental and organizational in our classification. However, Ross et al found "access to knowledge and information" to be a component of inner setting, which was added as an individual barrier (limited exposure/knowledge of eHealth) in our analysis. Another systematic review by O'Connor et al [43] analyzed qualitative studies to understand the factors affecting engagement with and recruitment to the use of eHealth applications. Bush et al [30] limited their systematic review to the pediatric population and the application type patient portal. The adoption of mHealth by health care professionals was the topic of the systematic review of Gagnon et al [33]. A narrative meta-review on e-mental health services was done by Batterham et al [17]. De Lusignan et al [32] did a literature review including electronic health records and patient access to health information, although eHealth applications were narrowed down to a subgroup.

In contrast to the studies included in our literature analysis, which were either based on literature analysis or reviews or experiences, we combined both expert discussions (experts' experience) and literature analysis. However, 24 success factors and one barrier from the expert discussions were not found in the literature. Also, the discussion groups "policy makers and politicians" and "data privacy officers and CIOs" could not be held due to a lack of participants.

Further approaches analyzed the applicability of the Technology Acceptance Model [13] and Unified Theory of Acceptance and Use of Technology [14,15] for the evaluation of eHealth services. However, these studies focused on contributing models for the evaluation of either eHealth services in general or a specific eHealth service instead of trying to provide a complete list of factors influencing their adoption. Models reflect only on certain details; they do not provide a holistic view of the impact factors for eHealth services.

Prior work includes analyses limited to within Europe, such as the Good eHealth Report [56] and MethoTelemed project [58]. The success factors given by the Good eHealth Report [56] are covered in the results of our literature analysis and expert discussions. Black et al [59] indicate that realizing the benefits of eHealth for quality and safety of health care is not guaranteed. They propose that more evaluation is necessary to identify all factors influencing eHealth services. The MethoTelemed project aimed to contribute to the evidence base on the impacts, benefits, and costs concerning telemedicine [58]. However, the project was constrained to telemedicine and focused mostly on methodological improvements.

In summary, the literature analysis conducted for this study, combined with findings from previous expert discussions, led to a more comprehensive list of barriers and facilitators for the adoption and implementation of eHealth services in general.

\section{Conclusions}

This work provides a comprehensive list of barriers and success factors based on two expert discussions and a literature analysis (see Multimedia Appendix 2). This list allows different stakeholders to address barriers and make use of facilitators in the planning phase of eHealth services. Thus, our work provides a valuable resource for health professionals, researchers, health care institutions, or consumers. With this resource, these groups might create better-suited applications and thus raise the adoption levels of consumer-centric eHealth services. Further studies on missing publications regarding the number of unsuccessful projects and eHealth services are necessary to research publication bias in this field.

\section{Acknowledgments}

We acknowledge financial support by Land Schleswig-Holstein within the funding program Open Access Publikationsfonds.

\section{Authors' Contributions}

BS did the literature analysis, contributed to the first expert discussion, participated in organizing the second expert discussion, combined the results from expert discussions and literature analysis, and wrote the paper draft. MP and MW organized the first and second expert discussion, gave input for the literature analysis, helped in combining the results from expert discussions and literature analysis, and reviewed and approved the paper. VS participated in the organization of the second expert discussion, gave input for the literature analysis, helped in combining the results from expert discussions and literature analysis, and reviewed and approved the paper. JS provided input, assisted in writing, and reviewed and approved the draft of the paper. BB gave input on the draft of the paper, and reviewed and approved the paper. 


\section{Conflicts of Interest}

None declared.

\section{Multimedia Appendix 1}

List of all 56 analyzed publications including extracted barriers and facilitators.

[XLSX File (Microsoft Excel File), 31 KB-Multimedia Appendix 1]

\section{Multimedia Appendix 2}

Mindmap of all barriers and facilitators identified in expert discussions and literature. [PDF File (Adobe PDF File), 3368 KB-Multimedia Appendix 2]

\section{References}

1. Mitchell J. From Telehealth to e-Health: The Unstoppable Rise of e-Health. Canberra, Australia: Department of Communications, Information Technology and the Arts; 1999:55-56.

2. Wildenbos GA, Peute LW, Jaspers MW. Impact of patient-centered eHealth applications on patient outcomes: a review on the mediating influence of human factor issues. Yearb Med Inform 2016 Nov 10(1):113-119 [FREE Full text] [doi: 10.15265/IY-2016-031] [Medline: 27830238]

3. Catwell L, Sheikh A. Evaluating eHealth interventions: the need for continuous systemic evaluation. PLoS Med 2009 Aug;6(8):e1000126 [FREE Full text] [doi: 10.1371/journal.pmed.1000126] [Medline: 19688038]

4. Elbert NJ, van Os-Medendorp H, van Renselaar W, Ekeland AG, Hakkaart-van Roijen L, Raat H, et al. Effectiveness and cost-effectiveness of ehealth interventions in somatic diseases: a systematic review of systematic reviews and meta-analyses. J Med Internet Res 2014 Apr 16;16(4):e110 [FREE Full text] [doi: 10.2196/jmir.2790] [Medline: 24739471]

5. Choi WS, Park J, Choi JY, Yang J. Stakeholders' resistance to telemedicine with focus on physicians: utilizing the Delphi technique. J Telemed Telecare 2019 Jul 01;25(6):378-385. [doi: 10.1177/1357633X18775853] [Medline: 29792080]

6. Adler-Milstein J, Kvedar J, Bates DW. Telehealth among US hospitals: several factors, including state reimbursement and licensure policies, influence adoption. Health Aff (Millwood) 2014 Feb;33(2):207-215. [doi: 10.1377/hlthaff.2013.1054] [Medline: 24493762]

7. Colditz GA. Economic costs of obesity and inactivity. Med Sci Sports Exerc 1999 Nov;31(11 Suppl):S663-S667. [Medline: 10593542]

8. Crouter SE, Schneider PL, Karabulut M, Bassett DRJ. Validity of 10 electronic pedometers for measuring steps, distance, and energy cost. Med Sci Sports Exerc 2003 Aug;35(8):1455-1460. [doi: 10.1249/01.MSS.0000078932.61440.A2] [Medline: 12900704]

9. OECD. Focus on Spending on Health: Latest Trends. 2018 Jun. URL: http://www.oecd.org/health/health-systems/ Health-Spending-Latest-Trends-Brief.pdf [accessed 2019-10-10]

10. Comstock J. Healthcare IT News. 2018 Jan 28. Apple to launch Health Records app with HL7's FHIR specifications at 12 hospitals. URL: https://www.healthcareitnews.com/news/apple-launch-health-records-app-hl7s-fhir-specifications-12-hospitals [accessed 2019-02-13] [WebCite Cache ID 76A8WdCVQ]

11. Naumann L, Babitsch B, Hübner U. Experts' insights into eHealth-legislation: comparing Switzerland and Germany. Stud Health Technol Inform 2018;253:148-152. [Medline: 30147061]

12. Davis FD, Bagozzi RP, Warshaw PR. User acceptance of computer technology: a comparison of two theoretical models. Manage Sci 1989 Aug;35(8):982-1003. [doi: 10.1287/mnsc.35.8.982]

13. Venkatesh V, Morris MG, Davis GB, Davis FD. User acceptance of information technology: toward a unified view. MIS Quart 2003;27(3):425-478. [doi: 10.2307/30036540]

14. Griebel L, Sedlmayr B, Prokosch HU, Criegee-Rieck M, Sedlmayr M. Key factors for a successful implementation of personalized e-health services. Stud Health Technol Inform 2013;192:965. [Medline: 23920739]

15. Hoque R, Sorwar G. Understanding factors influencing the adoption of mHealth by the elderly: an extension of the UTAUT model. Int J Med Inform 2017 May;101:75-84. [doi: 10.1016/j.ijmedinf.2017.02.002] [Medline: 28347450]

16. Rho MJ, Choi IY, Lee J. Predictive factors of telemedicine service acceptance and behavioral intention of physicians. Int J Med Inform 2014 Aug;83(8):559-571. [doi: 10.1016/j.ijmedinf.2014.05.005] [Medline: 24961820]

17. Batterham PJ, Sunderland M, Calear AL, Davey CG, Christensen H, Teesson M, et al. Developing a roadmap for the translation of e-mental health services for depression. Aust N Z J Psychiatry 2015 Sep 23;49(9):776-784. [doi: 10.1177/0004867415582054] [Medline: 25907269]

18. Hadjistavropoulos HD, Nugent MM, Dirkse D, Pugh N. Implementation of internet-delivered cognitive behavior therapy within community mental health clinics: a process evaluation using the consolidated framework for implementation research. BMC Psychiatry 2017 Sep 12;17(1):331 [FREE Full text] [doi: 10.1186/s12888-017-1496-7] [Medline: 28899365] 
19. Koivunen M, Hätönen H, Välimäki M. Barriers and facilitators influencing the implementation of an interactive Internet-portal application for patient education in psychiatric hospitals. Patient Educ Couns 2008 Mar;70(3):412-419. [doi: 10.1016/j.pec.2007.11.002] [Medline: 18079085$]$

20. Kruse CS, Atkins JM, Baker TD, Gonzales EN, Paul JL, Brooks M. Factors influencing the adoption of telemedicine for treatment of military veterans with post-traumatic stress disorder. J Rehabil Med 2018 May 08;50(5):385-392 [FREE Full text] [doi: 10.2340/16501977-2302] [Medline: 29700551]

21. Miake-Lye IM, Amulis A, Saliba D, Shekelle PG, Volkman LK, Ganz DA. Formative evaluation of the telecare fall prevention project for older veterans. BMC Health Serv Res 2011 May 23;11:119 [FREE Full text] [doi: 10.1186/1472-6963-11-119] [Medline: 21605438]

22. Mishuris RG, Stewart M, Fix GM, Marcello T, McInnes DK, Hogan TP, et al. Barriers to patient portal access among veterans receiving home-based primary care: a qualitative study. Health Expect 2015 Dec 12;18(6):2296-2305 [FREE Full text] [doi: 10.1111/hex.12199] [Medline: 24816246]

23. Band R, Bradbury K, Morton K, May C, Michie S, Mair FS, et al. Intervention planning for a digital intervention for self-management of hypertension: a theory-, evidence- and person-based approach. Implement Sci 2017 Feb 23;12(1):25 [FREE Full text] [doi: 10.1186/s13012-017-0553-4] [Medline: 28231840]

24. Mileski M, Kruse CS, Catalani J, Haderer T. Adopting telemedicine for the self-management of hypertension: systematic review. JMIR Med Inform 2017 Oct 24;5(4):e41 [FREE Full text] [doi: 10.2196/medinform.6603] [Medline: 29066424]

25. Shaw RJ, Kaufman MA, Bosworth HB, Weiner BJ, Zullig LL, Lee SD, et al. Organizational factors associated with readiness to implement and translate a primary care based telemedicine behavioral program to improve blood pressure control: the HTN-IMPROVE study. Implement Sci 2013 Sep 08;8:106 [FREE Full text] [doi: 10.1186/1748-5908-8-106] [Medline: 24010683]

26. Griebel L, Pobiruchin M, Wiesner M. Report on the MIE 2015 workshop: consumer health informatics-barriers and facilitators of eHealth usage among consumers. 2015 Aug Presented at: Report from: MIE2015 26th European Medical Informatics Conference; May 27-29, 2015; Madrid; p. 1-4. [doi: 10.13140/RG.2.1.2817.0081]

27. Ancker JS, Miller MC, Patel V, Kaushal R, HITEC Investigators. Sociotechnical challenges to developing technologies for patient access to health information exchange data. J Am Med Inform Assoc 2014;21(4):664-670 [REE Full text] [doi: 10.1136/amiajnl-2013-002073] [Medline: 24064443]

28. Ariens LF, Schussler-Raymakers FM, Frima C, Flinterman A, Hamminga E, Arents BW, et al. Barriers and facilitators to eHealth use in daily practice: perspectives of patients and professionals in dermatology. J Med Internet Res 2017 Sep 05;19(9):e300 [FREE Full text] [doi: 10.2196/jmir.7512] [Medline: 28874336]

29. Bello AK, Molzahn AE, Girard LP, Osman MA, Okpechi IG, Glassford J, et al. Patient and provider perspectives on the design and implementation of an electronic consultation system for kidney care delivery in Canada: a focus group study. BMJ Open 2017 Mar 02;7(3):e014784 [FREE Full text] [doi: 10.1136/bmjopen-2016-014784] [Medline: 28255097]

30. Bush RA, Connelly CD, Fuller M, Pérez A. Implementation of the integrated electronic patient portal in the pediatric population: a systematic review. Telemed J E Health 2016 Mar 10;22(2):144-152 [FREE Full text] [doi: 10.1089/tmj.2015.0033] [Medline: 26258289]

31. Cook EJ, Randhawa G, Sharp C, Ali N, Guppy A, Barton G, et al. Exploring the factors that influence the decision to adopt and engage with an integrated assistive telehealth and telecare service in Cambridgeshire, UK: a nested qualitative study of patient 'users' and 'non-users'. BMC Health Serv Res 2016 Apr 19;16:137 [FREE Full text] [doi: 10.1186/s12913-016-1379-5] [Medline: 27095102]

32. de Lusignan S, Ross P, Shifrin M, Hercigonja-Szekeres M, Seroussi B. A comparison of approaches to providing patients access to summary care records across old and new europe: an exploration of facilitators and barriers to implementation. Stud Health Technol Inform 2013;192:397-401. [Medline: 23920584]

33. Gagnon MP, Ngangue P, Payne-Gagnon J, Desmartis M. m-Health adoption by healthcare professionals: a systematic review. J Am Med Inform Assoc 2016 Jan;23(1):212-220. [doi: 10.1093/jamia/ocv052] [Medline: 26078410]

34. Garg SK, Lyles CR, Ackerman S, Handley MA, Schillinger D, Gourley G, et al. Qualitative analysis of programmatic initiatives to text patients with mobile devices in resource-limited health systems. BMC Med Inform Decis Mak 2016 Feb 06;16:16 [FREE Full text] [doi: 10.1186/s12911-016-0258-7] [Medline: 26851941]

35. Hao WR, Hsu YH, Chen KC, Li HC, Iqbal U, Nguyen PA, et al. LabPush: a pilot study of providing remote clinics with laboratory results via short message service (SMS) in Swaziland, Africa - a qualitative study. Comput Methods Programs Biomed 2015 Jan;118(1):77-83. [doi: 10.1016/j.cmpb.2014.10.005] [Medline: 25453385]

36. Hunting G, Shahid N, Sahakyan Y, Fan I, Moneypenny CR, Stanimirovic A, et al. A multi-level qualitative analysis of Telehomecare in Ontario: challenges and opportunities. BMC Health Serv Res 2015 Dec 09;15:544 [FREE Full text] [doi: 10.1186/s12913-015-1196-2] [Medline: 26645639]

37. Jimbo M, Shultz CG, Nease DE, Fetters MD, Power D, Ruffin MT. Perceived barriers and facilitators of using a Web-based interactive decision aid for colorectal cancer screening in community practice settings: findings from focus groups with primary care clinicians and medical office staff. J Med Internet Res 2013 Dec 18;15(12):e286 [FREE Full text] [doi: 10.2196/jmir.2914] [Medline: 24351420] 
38. Lennon MR, Bouamrane MM, Devlin AM, O'Connor S, O'Donnell C, Chetty U, et al. Readiness for delivering digital health at scale: lessons from a longitudinal qualitative evaluation of a national digital health innovation program in the United Kingdom. J Med Internet Res 2017 Feb 16;19(2):e42 [FREE Full text] [doi: 10.2196/jmir.6900] [Medline: 28209558]

39. Levine M, Richardson JE, Granieri E, Reid MC. Novel telemedicine technologies in geriatric chronic non-cancer pain: primary care providers' perspectives. Pain Med 2014 Feb;15(2):206-213 [FREE Full text] [doi: 10.1111/pme.12323] [Medline: 24341423]

40. Luque AE, van Keken A, Winters P, Keefer MC, Sanders M, Fiscella K. Barriers and facilitators of online patient portals to personal health records among persons living with HIV: formative research. JMIR Res Protoc 2013 Jan 22;2(1):e8 [FREE Full text] [doi: 10.2196/resprot.2302] [Medline: 23612564]

41. Makai P, Perry M, Robben SH, Schers H, Heinen M, Olde Rikkert MG, et al. Which frail older patients use online health communities and why? A mixed methods process evaluation of use of the Health and Welfare portal. J Med Internet Res 2014 Dec 17;16(12):e278 [FREE Full text] [doi: 10.2196/jmir.3609] [Medline: 25519769]

42. Molfenter T, Boyle M, Holloway D, Zwick J. Trends in telemedicine use in addiction treatment. Addict Sci Clin Pract 2015 May 28;10:14 [FREE Full text] [doi: 10.1186/s13722-015-0035-4] [Medline: 26016484]

43. O'Connor S, Hanlon P, O'Donnell CA, Garcia S, Glanville J, Mair FS. Understanding factors affecting patient and public engagement and recruitment to digital health interventions: a systematic review of qualitative studies. BMC Med Inform Decis Mak 2016 Sep 15;16(1):120 [FREE Full text] [doi: 10.1186/s12911-016-0359-3] [Medline: 27630020]

44. Ochoa AIII, Kitayama K, Uijtdehaage S, Vermillion M, Eaton M, Carpio F, et al. Patient and provider perspectives on the potential value and use of a bilingual online patient portal in a Spanish-speaking safety-net population. J Am Med Inform Assoc 2017 Nov 01;24(6):1160-1164. [doi: 10.1093/jamia/ocx040] [Medline: 28460130]

45. Odnoletkova I, Buysse H, Nobels F, Goderis G, Aertgeerts B, Annemans L, et al. Patient and provider acceptance of telecoaching in type 2 diabetes: a mixed-method study embedded in a randomised clinical trial. BMC Med Inform Decis Mak 2016 Nov 09;16(1):142 [FREE Full text] [doi: 10.1186/s12911-016-0383-3] [Medline: 27825340]

46. Popeski N, McKeen C, Khokhar B, Edwards A, Ghali WA, Sargious P, et al. Perceived barriers to and facilitators of patient-to-provider e-mail in the management of diabetes care. Can J Diabetes 2015 Dec;39(6):478-483. [doi: 10.1016/j.jcjd.2015.07.001] [Medline: 26409770]

47. Radhakrishnan K, Xie B, Jacelon CS. Unsustainable home telehealth: a Texas qualitative study. Gerontologist 2016 Oct;56(5):830-840. [doi: 10.1093/geront/gnv050] [Medline: 26035878]

48. Sarfo FS, Adamu S, Awuah D, Sarfo-Kantanka O, Ovbiagele B. Potential role of tele-rehabilitation to address barriers to implementation of physical therapy among West African stroke survivors: A cross-sectional survey. J Neurol Sci 2017 Oct 15;381:203-208 [FREE Full text] [doi: 10.1016/j.jns.2017.08.3265] [Medline: 28991682]

49. Schickedanz A, Huang D, Lopez A, Cheung E, Lyles CR, Bodenheimer T, et al. Access, interest, and attitudes toward electronic communication for health care among patients in the medical safety net. J Gen Intern Med 2013 Jul;28(7):914-920 [FREE Full text] [doi: 10.1007/s11606-012-2329-5] [Medline: 23423453]

50. Swinkels IC, Huygens MW, Schoenmakers TM, Oude Nijeweme-D'Hollosy W, van Velsen L, Vermeulen J, et al. Lessons learned from a living lab on the broad adoption of eHealth in primary health care. J Med Internet Res 2018 Mar 29;20(3):e83 [FREE Full text] [doi: 10.2196/jmir.9110] [Medline: 29599108]

51. Tieu L, Sarkar U, Schillinger D, Ralston JD, Ratanawongsa N, Pasick R, et al. Barriers and facilitators to online portal use among patients and caregivers in a safety net health care system: a qualitative study. J Med Internet Res 2015;17(12):e275 [FREE Full text] [doi: 10.2196/jmir.4847] [Medline: 26681155]

52. van Cranenburgh OD, Ter Stege JA, de Korte J, de Rie MA, Sprangers MA, Smets EM. Patient-reported outcome measurement in clinical dermatological practice: relevance and feasibility of a web-based portal. Dermatology 2016;232(1):64-70 [FREE Full text] [doi: 10.1159/000440613] [Medline: 26513574]

53. van der Meij E, Huirne JA, Ten Cate AD, Stockmann HB, Scholten PC, Davids PH, et al. A perioperative eHealth program to enhance postoperative recovery after abdominal surgery: process evaluation of a randomized controlled trial. J Med Internet Res 2018 Jan 02;20(1):e1 [FREE Full text] [doi: 10.2196/jmir.8338] [Medline: 29295808]

54. Varsi C, Ekstedt M, Gammon D, Ruland CM. Using the consolidated framework for implementation research to identify barriers and facilitators for the implementation of an internet-based patient-provider communication service in five settings: a qualitative study. J Med Internet Res 2015 Nov 18;17(11):e262 [FREE Full text] [doi: 10.2196/jmir.5091] [Medline: $\underline{26582138]}$

55. Wildenbos GA, Peute L, Jaspers M. Facilitators and barriers of electronic health record patient portal adoption by older adults: a literature study. Stud Health Technol Inform 2017;235:308-312. [Medline: 28423804]

56. European Commission. eHealth in Action-Good Practice in European Countries. Good eHealth Report. Luxembourg: Office for Official Publications of the European Communities; 2009.

57. Ross J, Stevenson F, Lau R, Murray E. Factors that influence the implementation of e-health: a systematic review of systematic reviews (an update). Implement Sci 2016 Oct 26;11(1):146 [FREE Full text] [doi: 10.1186/s13012-016-0510-7] [Medline: 27782832]

58. Ekeland AG, Bowes A, Flottorp S. Methodologies for assessing telemedicine: a systematic review of reviews. Int J Med Inform 2012 Jan;81(1):1-11. [doi: 10.1016/j.ijmedinf.2011.10.009] [Medline: 22104370] 
59. Black AD, Car J, Pagliari C, Anandan C, Cresswell K, Bokun T, et al. The impact of eHealth on the quality and safety of health care: a systematic overview. PLoS Med 2011 Jan 18;8(1):e1000387 [FREE Full text] [doi: 10.1371/journal.pmed.1000387] [Medline: 21267058]
Abbreviations
CIO: chief information officer
eHID: eHealth Innovation Days Conference
MIE: Medical Informatics Europe Conference

\author{
Edited by CL Parra-Calderón; submitted 29.03.19; peer-reviewed by MVR González, E Brainin, E Neter; comments to author 23.05.19; \\ revised version received 09.07.19; accepted 01.09.19; published 22.11.19 \\ Please cite as: \\ Schreiweis B, Pobiruchin M, Strotbaum V, Suleder J, Wiesner M, Bergh B \\ Barriers and Facilitators to the Implementation of eHealth Services: Systematic Literature Analysis \\ J Med Internet Res 2019;21(11):e14197 \\ URL: http://www.jmir.org/2019/11/e14197/ \\ doi: $10.2196 / 14197$ \\ PMID: 31755869
}

CBjörn Schreiweis, Monika Pobiruchin, Veronika Strotbaum, Julian Suleder, Martin Wiesner, Björn Bergh. Originally published in the Journal of Medical Internet Research (http://www.jmir.org), 22.11.2019. This is an open-access article distributed under the terms of the Creative Commons Attribution License (https://creativecommons.org/licenses/by/4.0/), which permits unrestricted use, distribution, and reproduction in any medium, provided the original work, first published in the Journal of Medical Internet Research, is properly cited. The complete bibliographic information, a link to the original publication on http://www.jmir.org/, as well as this copyright and license information must be included. 